\title{
Distribution of newly settled western rock lobsters Panulirus cygnus
}

\author{
P. Jernakoff* \\ CSIRO Division of Fisheries, PO Box 20, North Beach, WA 6020, Australia
}

\begin{abstract}
Little is known about the biology of the post-puerulus stage (i.e. individuals $<25 \mathrm{~mm}$ carapace length) of the commercially valuable western rock (spiny) lobster Panulirus cygnus, and few have been found in the field. In the present study, the natural habitat of post-pueruli was discovered through intensive diving surveys. Additional studies of habitat preference were carried out using a variety of designs of artificial habitats and the response of the post-pueruli to transferral between shelters was evaluated. Post-puerulus $P$. cygnus were found to shelter in small holes on the face, in ledges and in caves on coastal limestone reefs. They apparently preferred shelters with additional cover, typically seagrass and/or algae. Movement between shelters appeared common because $50 \%$ of monitored shelters were occupied for only a single day. Post-pueruli occurred in groups of up to 100 individuals, although $75 \%$ were solitary. There was a trend for larger post-pueruli to be gregarious. Two designs of artificial shelter were successfully utilised by post-pueruli: those made of 'Tanikalon' which resembled algae or seagrass, and those that consisted of holes in limestone blocks covered by seagrass. In transferral experiments, at least $50 \%$ of post-pueruli refused to enter or remain in new shelters after transfer from their previous shelters. This may be influenced by the method of release. Discovery of the natural habitat of post-puerulus $P$. cygnus means that it is now possible to study other aspects of their biology and population dynamics. Results of the transfer experiments indicate that future research is needed to determine the best release method to minimise rejection of new shelters. The successful utilisation of artificial habitats suggests that these habitats may have potential to enhance the survival of post-pueruli in areas where shelter is limited.
\end{abstract}

\section{INTRODUCTION}

Because of the commercial importance of the western (spiny) rock lobster Panulirus cygnus George, its biology and population dynamics have been intensively studied (e.g. Sheard 1962, Chittleborough 1970, Chittleborough \& Phillips 1975, 1979, Morgan 1979, Joll 1982, Phillips et al. 1984, Phillips 1986, Jernakoff et al. 1987). After a planktonic life of 9 to 11 mo the phylosoma larvae metamorphose offshore into pueruli (Chittleborough \& Thomas 1969). The pueruli swim to the coast to areas where limestone reefs are abundant (Chittleborough \& Phillips 1975) and peak settlement is between September to February each year (Phillips 1986). After settlement the pueruli acquire dark pigmentation and moult within a few days into postpueruli juveniles which are between 7.5 and $9 \mathrm{~mm}$

\footnotetext{
- Present address: Fisheries Resources Branch, Bureau of Rural Resources, Department of Primary Industries and Energy, Canberra, ACT 2006, Australia
}

carapace length (CL) (Phillips 1972). Juvenile lobsters, 2 to 5 yr old, inhabit the coastal areas, living in dens which are usually caves or ledges in the limestone reefs (Cobb 1981). When the lobsters are between 4 and $6 \mathrm{yr}$ old, they move offshore after the spring moult, to adult habitats in depths of 30 to $150 \mathrm{~m}$ (Morgan et al. 1982).

Although the stages of the life cycle have been identified, the post-puerulus stage has rarely been found in its natural habitat despite numerous attempts. These have included electrofishing (Phillips \& Scolaro 1980), baited traps, beam trawls and ad hoc searching by divers (B. Phillips, CSIRO Marine Laboratories, pers. comm.). The successful use of artificial seaweed collectors to collect pueruli and post-pueruli (Phillips 1972) means, however, that limited information on their biology is available - for example the post-pueruli of Panulirus cygnus are cryptically coloured with a pattern similar to post-pueruli of other panulirid species [e.g. P. interruptus (Randall): Engle 1979; P. argus (Latrielle): Lewis et al. 1952, Andree 1981, Marx \& Herrnkind 1985a,b]. From the results of laboratory 
studies, Phillips et al. (1977) suggested that postpueruli of $P$. cygnus are probably solitary, living in shallow coastal seagrass beds, and that at about $25 \mathrm{~mm}$ $\mathrm{CL}$ they become gregarious and move from the seagrass beds to the nursery reefs.

The natural habitats of the post-pueruli of Panulirus interruptus and $P$. argus, unlike that of $P$. cygnus, have been described. Andree (1981), Marx (1983) and Hermkind \& Butler (1986) reported that the postpueruli of $P$. argus in Florida, USA, are found in clumps of Laurencia spp. (red algae) and algal-covered rock rubble; they have also been found on algal-covered mangrove roots (Witham et al. 1964). The post-pueruli of $P$. interruptus in California, USA, live in Phyllospadix seagrass beds in predominantly rocky habitats with dense plant cover (Parker 1972, Serfling 1972, Engle 1979). The success in finding the habitats of postpueruli of $P$. argus and $P$. interruptus was due to intensive searches by SCUBA divers (e.g. Serfling 1972, Engle 1979, Marx 1983). It has also led to studies of factors affecting their ecology e.g. food and shelter (Marx \& Herrnkind 1985a). The lack of success in finding post-pueruli of $P$. cygnus in their natural habitat has made direct studies of their ecology and population dynamics impossible. The aim of the present study was, therefore, to redress the gaps in the knowledge of the natural habitat and habitat preference of post-puerulus $P$. cygnus. A related aspect of the study was to evaluate whether the lobsters can be successfully transferred between habitats. Chittleborough \& Phillips (1975) suggested that transferral of individuals may be a way to increase the abundance of rock lobsters in areas of poor natural settlement. Various designs of artificial habitats were also evaluated to determine which if any artificial habitats are successfully utilised by post-pueruli. A methodical use of divers to search for $P$. cygnus in their natural habitat seemed appropriate in this study, given the successful use of divers in locating other species (e.g. Serfling 1972, Engle 1979, Marx 1983).

\section{MATERIALS AND METHODS}

Study site. The study was carried out at Seven Mile Beach in Western Australia $\left(29^{\circ} 08^{\prime} \mathrm{S}, 114^{\circ} 54^{\prime} \mathrm{E}\right.$ ), a site in the centre of the geographical range of Panulirus cygnus. Pueruli and post-pueruli are regularly found at this site on floating artificial seaweed collectors (Phillips 1972) moored near patch reefs and seagrass in water 2 to $5 \mathrm{~m}$ deep. Limestone patch reefs and seagrass, interspersed with patches of sand and rock rubble, are found at Seven Mile Beach and are typical of the coastal areas where juvenile western rock lobsters are found (Fig. 1). The main habitat features of the reefs are the tops, the reef face, caves and ledges.

The flat tops of the patch reefs are generally 1 to $2 \mathrm{~m}$ below the surface of the water except during low spring tides. Seagrasses, Amphibolis antarctica (Labill)

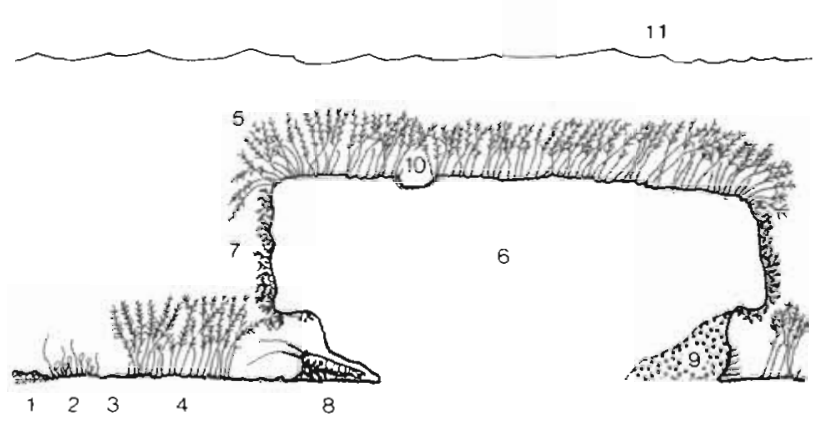

Fig. 1. Schematic diagram showing main habitat features in shallow coastal areas at Seven Mile Beach, Western Australia. $1=$ rock rubble; $2=$ Heterozostera/Halophila seagrass; $3=$ sand $_{\text {i }} 4=$ Amphibolis seagrass on the seabed; $5=$ Amphibolis seagrass on the reef top; $6=$ the limestone reef; $7=$ the reef face with algal cover; $8=$ a ledge sheltering a juvenile rock lobster $; 9=$ a cave; $10=$ a patch of bare limestone reef; and $11=$ the sea surface

Sond. \& Asch. ex Asch. and A. griffithii (Black) den Hartog, usually cover the reef tops, although small patches of the reefs may be bare. Epiphytic coralline algae, sponges and non-coralline algae grow on the seagrasses and on patches on the reef devoid of seagrass (Fig. 1).

Some areas of the reef face are bare limestone, while other parts are covered by seagrass and algae. The face is usually either vertical, or slopes gently to the sea floor, and patches of large green algae (e.g. Caulerpa sp. and Codium sp.) may cover the entrance of ledges and caves.

Ledges are found on the face and at the base of the reefs and generally have a horizontal floor of bare limestone or sand (Fig. 1). They are usually between $1 \mathrm{~cm}$ and $1 \mathrm{~m}$ high, and up to several metres wide. They are open at the sides and have a sloping roof extending into the reef to a depth of about $1 \mathrm{~m}$; there are often small ledges within larger ledges. Detritus periodically fills ledges and caves at the base of reefs (depending upon water movements).

Caves are similar to ledges except they are not open at the sides and usually extend into the reefs to a depth of up to 2 or $2.5 \mathrm{~m}$ (Fig. 1). There is probably less water movement and light in caves than in the ledges ( $P$. Jernakoff pers. obs.). The roofs of caves, as of the ledges, are either bare limestone or covered by sponges, ascidians, bryozoans, tubeworms and epiphytic algae. Caves have a sand substratum and may have small ledges on their walls. 
Seagrass beds consisting of either Amphibolis antarctica and A. griffithii, or Heterozostera tasmanica (Martens ex Asch.) den Hartog, and Halophila ovalis (Brown) Hooker, interspersed with patches of sand and small outcrops of algal-covered rock or rubble, separate the reefs (Fig. 1). The $A$. antarctica and A. griffithii canopy is dense and ca $40 \mathrm{~cm}$ tall. The canopy of Heterozostera/Halophila seagrasses, however, is sparse and no more than $10 \mathrm{~cm}$ high, and is often interspersed with various algae e.g. Caulerpa spp.

Post-pueruli surveys. Other species of post-pueruli have been found living in algal and seagrass habitats (Parker 1972, Serfling 1972, Engle 1979, Andree 1981, Marx 1983, Herrnkind \& Butler 1986). Phillips et al. (1977) suggested that seagrass beds were the likely habitat of post-pueruli of Panulirus cygnus, and because seagrass beds are a dominant feature of the coastal areas of Western Australia, and are abundant at Seven Mile Beach, they were the first habitat searched. Various searching methods were used, some based on methods tried by other workers overseas (e.g. Sweat 1968, Engle 1979); beam trawls were not tried because this technique has proved unsuccessful in the past ( $B$. Phillips, CSIRO Marine Laboratories, pers. comm.).

Seagrass beds were surveyed in October 1986 using modified $1 \mathrm{~m}^{2}$ steel quadrats. Quadrats were constructed of a $40 \mathrm{~cm}$ high fence of flexible plastic mesh $(1.5 \times 3 \mathrm{~mm}$ mesh) supported by floats; the $15 \mathrm{~cm}$ wide bottom skirt was weighted with chain to prevent escape of post-pueruli around the bottom of the quadrat. A total of 136 quadrats were sampled. Quadrats were grouped in blocks of 4 for ease of sampling and to evaluate whether a sampling scale of $2 \times 2 \mathrm{~m}$ was more appropriate than separate $1 \mathrm{~m}^{2}$ quadrats. Twenty-nine blocks of 4 quadrats each were haphazardly placed in Amphibolis seagrass on the seabed, with another 5 blocks of 4 quadrats in Amphibolis seagrass growing on the top of 5 separate reefs. Because the post-pueruli are small and cryptic, 2 divers were used side by side to search each quadrat twice, once in a north-south and once in an east-west direction. This minimised the possibility of post-pueruli moving from one section of the quadrat to another and being missed by a single diver, and maximised the probability that all postpueruli were counted.

Because Amphibolis seagrass beds are very thick, it is possible, even using the above sampling method, that post-pueruli may have been missed by the divers. To examine this possibility, the entire contents of 60 quadrats, 20 on the tops of reefs and 40 on the seabed, were removed (after searching) by cutting the seagrass stems and using a suction pump to suck the canopy, stems and sand substratum to a depth of about $2 \mathrm{~cm}$ into a plastic mesh bag $(1.5 \times 3 \mathrm{~mm}$ mesh). The samples were then taken ashore and searched. In addition, fourteen $10 \times 0.5 \mathrm{~m}$, and one $6 \times 0.5 \mathrm{~m}$, transects were searched by divers without the use of fenced quadrats or suction pumps. During April 1987, 28 additional quadrats (12 on reef tops and 16 on the seabed) were searched and suctioned using the same methods used during October 1986.

Removal of the Heterozostera and Halophila canopy was unnecessary because these seagrass beds are very sparse (Fig. 1) and are easily searched. A total of 32 quadrats were searched in October 1986 by pairs of divers in the same way as previously described. Any post-pueruli could be easily seen by divers, who also probed the substratum in case post-pueruli were buried in the sand.

During November 1986, divers also systematically searched (without quadrats) a total of $40 \mathrm{~m}^{2}$ of reef top, $55.5 \mathrm{~m}^{2}$ of rock rubble and $87 \mathrm{~m}^{2}$ of caves. The numbers and estimated size of post-pueruli were recorded. At this time, the sizes of lobsters were estimated in size classes of $<10 \mathrm{~mm}, 10$ to $<15 \mathrm{~mm}, 15$ to $<20 \mathrm{~mm}$, and 20 to $<25 \mathrm{~mm}$ CL.

Eleven reefs were searched during both February 1987 and March-April 1987. Seven of these reefs were sampled during both periods (i.e. 4 of the reefs sampled during March-April were different from those sampled in February). Habitats consisted of caves, ledges, the reef face, and Amphibolis growing on the reef top (see Fig. 1). The actual sizes of post-pueruli were estimated by divers who by this time had more experience in estimating the sizes of the lobsters. Preliminary checks indicated that the divers' estimates were generally within $2 \mathrm{~mm}$ of the measured carapace lengths. Density estimates (per $\mathrm{m}^{2}$ ) of caves, ledges and the reef face were made by divers using torches to assist in their search. As the areas searched were estimated and did not include the rugosity and microtopography of the reef surface, the real surface area searched is underestimated.

In addition to density surveys, the type of cover immediately adjacent to the shelter sites (hereafter called shelters) was recorded during November 1986. The occupancy rate of 52 marked shelters on 5 reefs was also followed for a period of $16 \mathrm{~d}$ during November 1986 by divers who observed whether or not the marked shelters were occupied on a daily basis

Habitat preference experiments. To determine whether post-pueruli would accept artificial shelters, 4 designs of shelters (Fig. 2) were constructed to mimic either seagrass or holes in rocks, and were roughly based on designs used by Sweat (1968).

The first type of artificial shelter was a hollow concrete cylinder (70 $\mathrm{mm}$ diameter) with 12 holes $(20 \mathrm{~mm}$ diameter). The ends of the cylinder were sealed with plastic mesh to allow water movement but exclude predatory octopi and fish (Fig. 2). The second type 


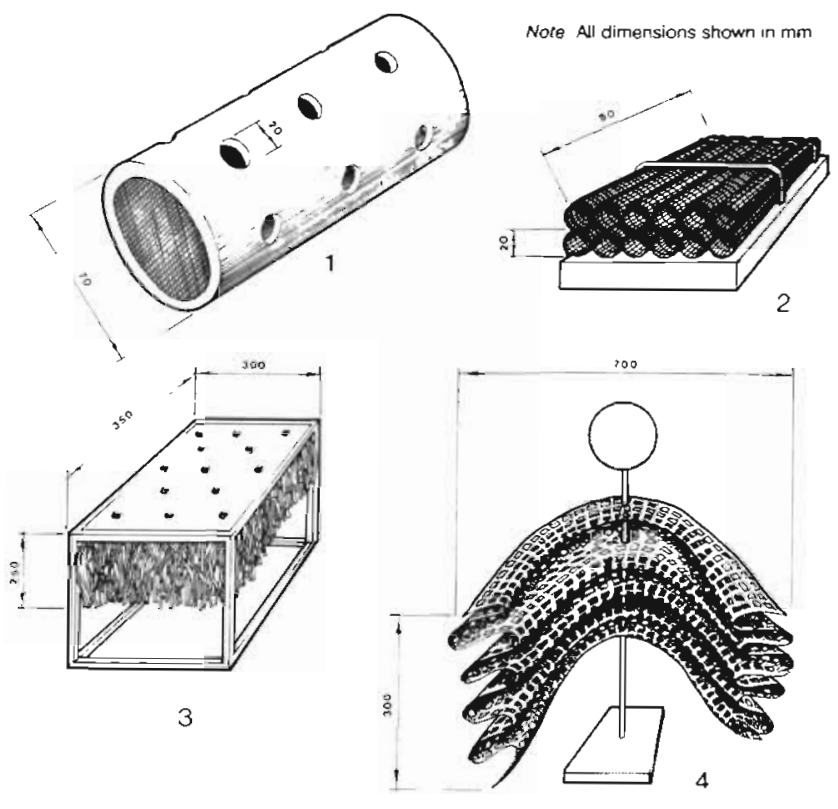

Fig. 2. Artificial shelters used at Seven Mile Beach. Type 1 is a concrete cylinder with 12 holes drilled in it; both ends are blocked with plastic mesh. Type 2 is a block of 12 PVC mesh cylinders clamped at one end and wired to a steel weight. Type 3 is a mat of 'Tanikalon' attached to a plastic sheet mounted on a steel frame. Type 4 is a concertina of fibre mesh on a rope suspended between a float and a steel weight

of artificial shelter was a block of 12 PVC mesh $(1.5 \times 3 \mathrm{~mm}$ mesh $)$ cylinders, $20 \mathrm{~mm}$ diameter $\times 80 \mathrm{~mm}$ length, clamped at one end and strapped together on a flat steel anchor (Fig. 2). The third type consisted of a mat of 'Tanikalon' (Taniyama Chemical Industries Ltd. Okayama, Japan) synthetic fibres $(350 \times 300 \times 250 \mathrm{~mm})$ attached to a plastic sheet, as is used in puerulus collectors (Phillips 1972), mounted on a steel frame such that the fibres were hanging down (Fig. 2). The fourth type consisted of a concertina (ca $300 \mathrm{~mm}$ diameter $\times 700 \mathrm{~mm}$ long) of a fibre mesh, suspended on a rope between a float and flat steel anchor (Fig. 2).

Five of each of these types of shelters were haphazardly placed at 2 sites, $750 \mathrm{~m}$ apart within Amphibolis, during October 1986. The habitats were sampled for pueruli and post-pueruli in November 1986, February 1987 and March 1987. The concrete cylinders and PVC mesh cylinders were searched in situ by divers using torches to illuminate the shelters. The 'Tanikalon' and fibre mesh shelters were checked in situ and then carefully lifted onto a boat for more detailed sampling, after which the shelters were returned to their sites. No post-pueruli were ever observed by divers to flee these shelters during checking or removal of the shelters to the boat. The numbers of pueruli and post-pueruli found in the artificial shelters and 5 control plots of Amphibolis (each ca $300 \times 300 \mathrm{~mm}$ ) at each site was recorded and the lobsters removed.

Preliminary observations in November 1986 indicated that 2 factors appeared to influence shelter preference: the size of shelter and the presence of immediately adjacent cover. An experiment using holes drilled in blocks of quarried local limestone was designed to test whether these factors significantly influenced the choice of shelter. Twelve blocks were used, each $60 \mathrm{~cm}$ long $\times 30 \mathrm{~cm}$ wide $\times 25 \mathrm{~cm}$ high. Holes of $8,10,12$, or $14 \mathrm{~mm}$ diameter and either 25 or $50 \mathrm{~mm}$ deep were drilled in each block. The holes were drilled $100 \mathrm{~mm}$ apart over the sides of each block, with the size and diameter of holes randomly assigned within a grid. There were 4 replicates of each hole size and diameter per block (i.e. a total of 32 holes), thus these treatments tested for the effects of hole size and diameter on shelter preference of post-pueruli.

The effects of cover around the limestone block shelter was also tested by placing all of the 12 blocks in thick Amphibolis seagrass beds $(6$ blocks at one site and 6 at a second site $750 \mathrm{~m}$ away) and then cutting away the seagrass from 3 of the blocks at each site. In this way, all of the blocks were situated within seagrass beds but only half of the blocks were covered by seagrass; the other 6 blocks were bare.

The holes in the blocks were checked by divers with torches 5 times between 11 December 1986 and 21 November 1987 . Presence and estimated size of postpueruli were recorded and the lobsters were then removed and relocated away from the area.

Post-pueruli transferral experiments. Attempts to restock areas of poor natural settlement require a knowledge of how post-pueruli respond when transferred between habitats. In a series of studies, postpueruli of $<15 \mathrm{~mm} \mathrm{CL}$ were transferred between artificial shelters, from artificial to natural shelters and between natural shelters. Their responses (i.e. whether they stayed or rejected their new shelters) were recorded.

It was found that some lobsters naturally vacated their shelters after only a single night (see 'Results') Post-pueruli were observed to be active only at night, remaining within the shelters during the day ( $P$. Jernakoff unpubl. data). It is possible that a shelter vacated by one individual may be reoccupied by another during the same night. Lobsters found in the same shelter on the following day could not, therefore, be identified as the same individual. Unfortunately, postpueruli could not be individually marked because marking requires gripping them firmly. This often results in injury, because of their small size, and apparent stress as evidenced by their observed reluctance to 
enter and remain in their shelters (see 'Results'). Consequently, comparisons of the shelter occupancy of transferred (disturbed) and control (undisturbed) lobsters provide somewhat ambiguous conclusions.

In the first experiment, 20 post-pueruli were individually transferred in clear plastic water-filled bottles from artificial seaweed collectors (Phillips 1972) to natural holes in the limestone reef, and 12 individuals were transferred to $14 \mathrm{~mm}$ diameter, $50 \mathrm{~mm}$ deep holes in limestone blocks ( 2 post-pueruli per block). The blocks ( $60 \mathrm{~cm}$ long $\times 30 \mathrm{~cm}$ wide $\times 25 \mathrm{~cm}$ high) had been placed in Amphibolis seagrass beds a month before, and were lightly colonised by epibenthos. Lobsters were observed for up to $1 \mathrm{~h}$ after release to determine whether they remained in their new shelters, and the shelters were checked in the morning of the following day to determine whether or not the shelters were occupied.

In the second experiment, the effect of transferral (disturbance) was examined by taking post-pueruli from natural shelters and returning them to the same shelters. Seventeen post-pueruli were taken from their individual shelters on a limestone reef by inserting a small length of wire between the body of the postpuerulus and the wall of the shelter and then tapping the side of the individual with the wire. This caused the post-puerulus to flee its shelter into a clear plastic water-filled bottle held over the entrance to the hole. Post-pueruli were released at their own shelters within 3 min of capture. Post-pueruli were released using 2 different techniques. In 8 cases, a bottle was held directly over the shelter so that the edge was in contact with the limestone reef; thus a post-puerulus could only stay in its bottle or re-enter its shelter until the bottle was removed (after about $3 \mathrm{~min}$ ). In the other 9 cases, due to a misunderstanding between divers, the bottles were placed over the shelters at a $45^{\circ}$ angle so that they did not seal with the substratum. In this case, postpueruli could either go back into their shelters or move immediately into the surrounding seagrass. Animals and shelters, in addition to a control group of 15 undisturbed post-pueruli in natural shelters, were observed in an identical manner as in the first study.

The third experiment tested the effects of transferral (disturbance) of post-pueruli by taking them from their shelters in limestone blocks and then returning them to their own shelters. Divers took 8 out of the 16 postpueruli that were naturally occupying holes in limestone blocks and then returned them to their own shelters within 3 min of capture. Post-pueruli were held in bottles and then released by holding the bottles at a $45^{\circ}$ angle so that they had a choice of either re-entering the holes or escaping into the surrounding seagrass. The 8 transferred and 8 control lobsters and shelters were checked as previously described.

\section{RESULTS}

\section{Post-pueruli surveys}

During October 1986, no post-pueruli were found in seagrass beds during quadrat and transect sampling. In November 1986, 188 post-pueruli were found on reefs in caves $(n=51)$, ledges $(n=110)$ and on the reef face $(\mathrm{n}=27)$. No lobsters were found sheltering in seagrass on reefs or in seagrass beds between the reefs. Most $(60.1 \%)$ of the post-pueruli were between 10 and $15 \mathrm{~mm} \mathrm{CL}$, while $23.4 \%$ were $<10 \mathrm{~mm}, 10.1 \%$ were between 15 and $20 \mathrm{~mm}$, and $6.4 \%$ were between 20 and $25 \mathrm{~mm} \mathrm{CL}$.

In February 1987 the areas searched consisted of $248 \mathrm{~m}^{2}$ of caves, $701 \mathrm{~m}^{2}$ of ledge, $489 \mathrm{~m}^{2}$ of reef face and $622 \mathrm{~m}^{2}$ of Amphibolis. In March-April 1987, the areas searched were $90 \mathrm{~m}^{2}$ of cave, $373 \mathrm{~m}^{2}$ of ledge, $277 \mathrm{~m}^{2}$ of reef face and $791 \mathrm{~m}^{2}$ of Amphibolis. No postpueruli were found sheltering amongst Amphibolis during February 1987 and only 2 individuals were found in this habitat during March-April 1987; this habitat was excluded from statistical analyses.

A balanced, orthogonal analysis of variance (ANOVA) to determine whether the densities in the 3 habitats were independent of the particular reef being sampled was constrained because some habitats were absent on some patch reefs (e.g. not all reefs had caves). It was, however, possible to analyse a subset of the March-April 1987 density data on reefs with all 3 habitats present. In February 1987, the subset of data on reefs with all 3 habitats was too small to test statistically.

Analysis of a subset of the March-April 1987 data indicated no significant interaction in the density of post-pueruli in the 3 types of habitats and the reefs ( $\mathrm{p}=$ $0.89, \mathrm{df}=20,66)$. Thus the effects of habitats were assumed to be independent of the effects of reef, therefore data from all reefs could be pooled to increase the power of the ANOVA to test for significant differences in the density of post-pueruli between habitats. Likewise, data from all habitats could be pooled to test whether reefs had significantly different densities. The independence of habitats and reefs was also assumed for February 1987, enabling separate analyses of reefs (pooling data from all habitats) and habitats (pooling data from all reefs).

In February 1987, there was no significant difference (ANOVA, $p=0.98$, df $=2,162$ ) in the densities of postpueruli found on the reef face (mean $=0.57$ ind. $\mathrm{m}^{-2}$, $\mathrm{n}=56$ ), ledges (mean $=0.57$ ind $\mathrm{m}^{-2}, \mathrm{n}=65$ ), or caves (mean $=0.64$ ind. $\mathrm{m}^{-2}, \mathrm{n}=44$ ). However, in March-April 1987 there were significant differences in the densities between habitats (ANOVA, $\mathrm{p}=0.01, \mathrm{df}=$ 2,107 ). The densities on the reef face (mean $=0.51$ ind. 
$m^{-2}, n=38$ ) were significantly less than in caves (mean $=0.91$ ind $\mathrm{m}^{-2}, \mathrm{n}=20$ ) which were significantly less than in ledges (mean $=1.36$ ind $\mathrm{m}^{-2}, \mathrm{n}=52$; StudentNewman-Keuls [SNK] test, $\mathrm{p}=0.05$ ).

While the densities of post-pueruli on the reef face were similar during February 1987 and March-April 1987, the densities of post-pueruli in ledges and caves were higher in March-April 1987.

There was significant variation in the densities per $\mathrm{m}^{2}$ of post-pueruli between reefs during the February sampling (ANOVA, $\mathrm{p}<0.01, \mathrm{df}=10,130$ ). The results of an SNK test ( $p=0.05$ ) indicated that the reefs could be split into 3 groups on the basis of their mean densities per $\mathrm{m}^{2}$. Reefs 45, 3, 29 and 35 (range $=0.09$ to 0.20 ind $\mathrm{m}^{-2}$ ) had significantly lower densities than Reefs $5,22,21$ and 17 (range $=0.42$ to 0.47 ind $\mathrm{m}^{-2}$ ) which were lower than densities on Reefs $1 \mathrm{~s}, 1 \mathrm{n}$ and 4 (range $=1.21$ to 1.49 ind. $\mathrm{m}^{-2}$ ). Reefs $1 \mathrm{~s}, 1 \mathrm{n}$ and 4 were within $50 \mathrm{~m}$ of each other whereas the other 2 groups of reefs were interspersed. During March-April, there was no significant difference in the densities per $\mathrm{m}^{2}$ (ANOVA, $p=0.10, \mathrm{df}=10,88$ ). Mean reef densities for the 7 reefs sampled during both periods (Reefs $1 \mathrm{~s}, 1 \mathrm{n}, 5$, 21, 22, 29 and 45) were generally higher in MarchApril (range $=0.57$ to 1.69 ind. $\mathrm{m}^{-2}$ ) than in February (range $=0.09$ to 1.49 ind $\mathrm{m}^{-2}$ ).

In February 1987, the sizes of post-pueruli in caves (mean size $=16.4 \mathrm{~mm} \mathrm{CL}, \mathrm{n}=107$ ) were not significantly different than those in ledges (mean size = $16.0 \mathrm{~mm} \mathrm{CL}, \mathrm{n}=249$ ), and both were significantly larger than those on the reef face (mean size $=14.6 \mathrm{~mm}$ $\mathrm{CL}, \mathrm{n}=67$; ANOVA, $\mathrm{p}<0.01, \mathrm{df}=2,464$, and SNK test, $p=0.05$ ). Analysis of the sizes of post-pueruli in March-April 1987 indicated that individuals in caves (mean size $=20.3 \mathrm{~mm} \mathrm{CL}, \mathrm{n}=51$ ) were significantly larger than those of both ledges (mean size $=18.3 \mathrm{~mm}$ $\mathrm{CL}, \mathrm{n}=254$ ) and the reef face (mean size $=18.4 \mathrm{~mm}$ $\mathrm{CL}, \mathrm{n}=107 ;$ ANOVA, $\mathrm{p}<0.01, \mathrm{df}=2,409$, and SNK test, $p=0.05$ ). The sizes of post-pueruli had significantly increased between February 1987 and March-April 1987 (Kolmogorov Smirnov analyses, $p<0.01$; caves, $D=0.39 ;$ ledges, $D=0.21$; reef face $\mathrm{D}=0.40)$.

\section{Cover around the shelter}

Cover around shelters consisted mainly of Amphibolis, a range of algal species (see Appendix 1), or a combination of Amphibolis and algae. There were also small amounts of unidentified species of sponges (mainly in caves), and detritus (Fig. 3). Proportionally fewer post-pueruli $<15 \mathrm{~mm}$ CL were in bare shelters (Fig. 3), all of which were on ledges or in caves. No post-pueruli $<10 \mathrm{~mm} \mathrm{CL}$ were found in shelters covered by detritus.

\section{Fidelity to shelters}

Most of the shelters were occupied by post-pueruli $<15 \mathrm{~mm}$ CL. As the lobsters were not marked (because any disturbance might influence their fidelity to a shelter) it was not possible to be certain that occupants on the following day were the same individual. Approximately $50 \%$ of shelters were occupied for 2 or more consecutive days and $20 \%$ were occupied for more than 10 consecutive days (Fig. 4). Three shelters were occupied for at least 16 consecutive days, 2 for at least 15 consecutive days, 1 each for at least 10 , 12 and 14 consecutive days.

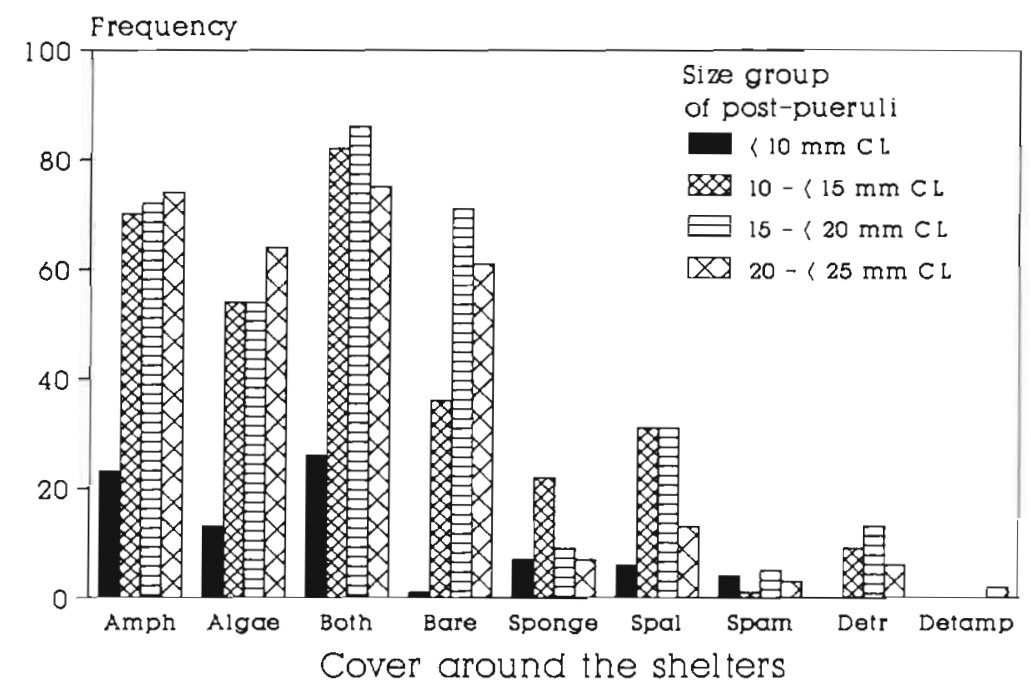

Fig. 3. Cover immediately adjacent to shelters at Seven Mile Beach. 'Amph'. Amphibolis; 'Both' cover of both algae and Amphibolis; 'Bare' areas bare of cover; 'Spal': cover of both sponges and algae; 'Spam': cover of both sponges and Amphibolis; 'Detr': detritus; 'Detamp' cover of detritus and Amphibolis 


\section{Gregariousness within shelters}

Of the 265 post-pueruli, $75 \%$ were solitary (Fig. 5). In 30 cases, lobsters were found in pairs, and on 8 occasions there were 10 or more post-pueruli in a group. The largest group had about 100 individuals in a small hole $\left(0.25 \mathrm{~m}^{2}\right.$ surface area) in the reef face. Of these, 93 were captured and measured; 7 were juveniles between 25 and $31 \mathrm{~mm} \mathrm{CL}$, and the remainder were post-pueruli between 10 and $25 \mathrm{~mm} \mathrm{CL} \mathrm{(Fig.} \mathrm{6).}$ Although these data indicate that a range of sizes may occupy a single shelter, subsequent sampling by Fitzpatrick (CSIRO Marine Laboratories; see Fig. 7), using sampling methods identical to those in the present study, indicate that there is a trend for smaller postpueruli to be solitary and larger animals to be gregarious.

\section{Experiments on habitat preference}

Of the 4 designs of artificial shelter (Fig. 2) postpueruli were only found in those made of 'Tanikalon' which is used to make the artificial seaweed collectors. No post-pueruli were found in control plots of Amphibolis. A 2-factor ANOVA of the density of postpueruli per 'Tanikalon' shelter indicated that there was no significant interaction between sites and sampling times $(\mathrm{p}=0.56$, df $=2.24)$. There were, however, significantly more post-pueruli per shelter $(p<0.05$, $\mathrm{df}=2,24)$ in March-April 1987 (mean $=1.34, \mathrm{n}=10$ ) compared with February 1987 (mean $=1.01, \mathrm{n}=10)$, and more in February 1987 than in November 1986 (mean $=0.80, \mathrm{n}=10)$. Also significantly more postpueruli ( $p<0.001$, df $=1,24$ ) were found at 1 of the 2 sampling sites (Site 1 mean $=0.85, \mathrm{n}=15$; Site 2 mean $=1.24, \mathrm{n}=15$.

\section{Limestone blocks}

All 35 post-pueruli found in holes in the limestone blocks were between 7 and $12 \mathrm{~mm} \mathrm{CL}$ (mean $=9.9 \mathrm{~mm}$ ). Although this experiment was originally designed to be analysed by ANOVA (factors being times, sites, seagrass cover, hole size and hole depth) this analysis was unnecessary because of several clear-cut results. Postpueruli preferred holes in blocks with seagrass cover compared to bare shelters ( $\mathrm{n}=35$ with seagrass cover, $\mathrm{n}$ $=0$ without cover). In addition, there was a strong preference for the deeper holes ( $\mathrm{n}=34$ for $50 \mathrm{~mm}$ deep holes, $\mathrm{n}=1$ for $25 \mathrm{~mm}$ deep holes). There was no significant difference in the numbers of post-pueruli found between the 5 sampling times and the 2 sites (contingency table analysis, $\mathrm{G}=2.84, \mathrm{df}=4, \mathrm{p}=0.59$ ),

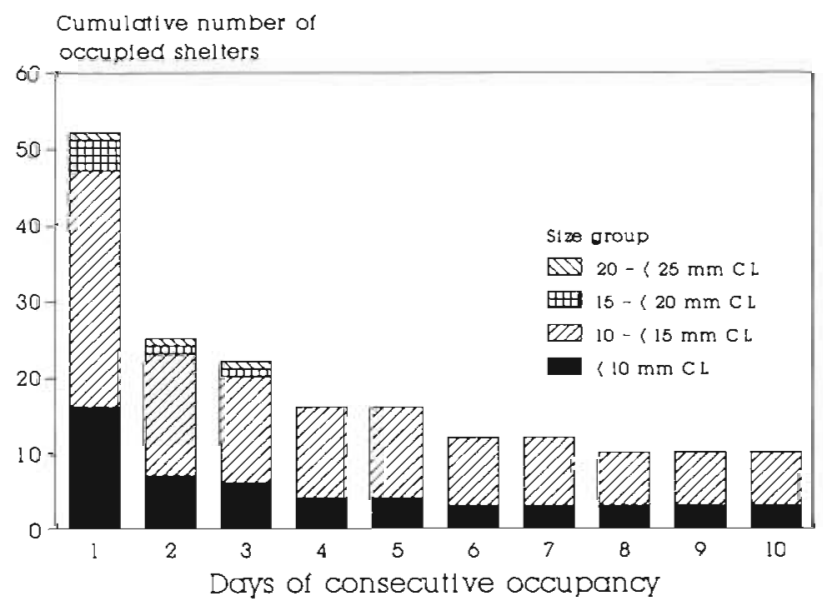

Fig. 4. Panulirus cygnus. Occupancy of natural shelters by size groups of post-pueruli at Seven Mile Beach during November 1986

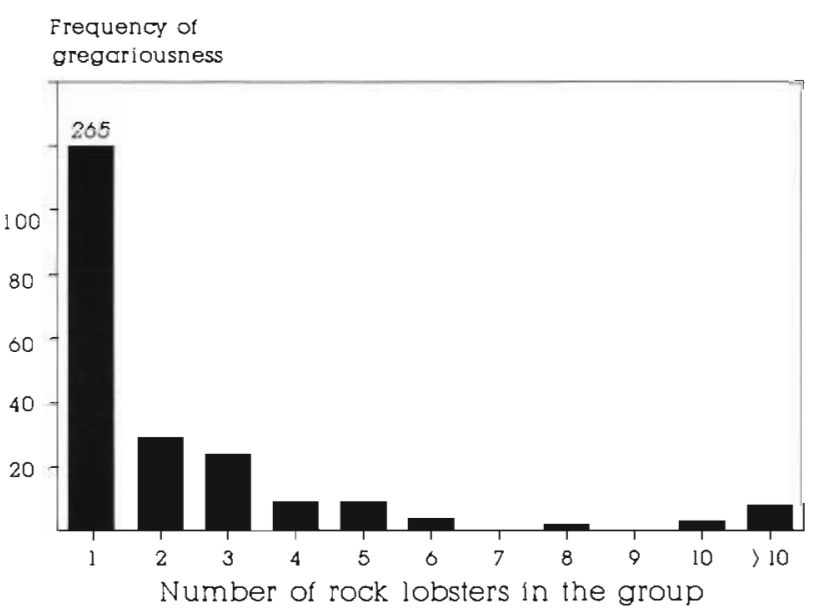

Fig. 5. Panulirus cygnus. Frequency of gregariousness of postpueruli in natural shelters at Seven Mile Beach during February 1987

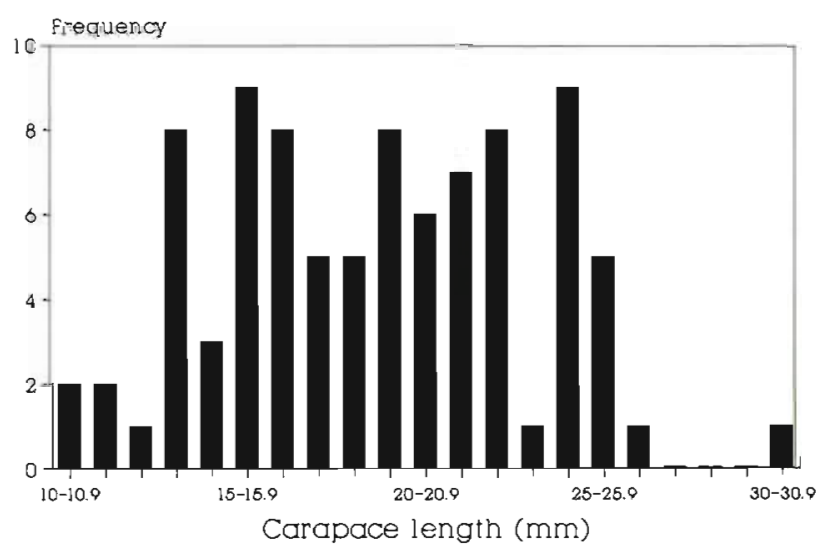

Fig. 6. Panulirus cygnus. Size range of 86 post-pueruli and 7 juveniles (greater than $25 \mathrm{~mm}$ CL) found together in one natural shelter at Seven Mile Beach during February 1987 


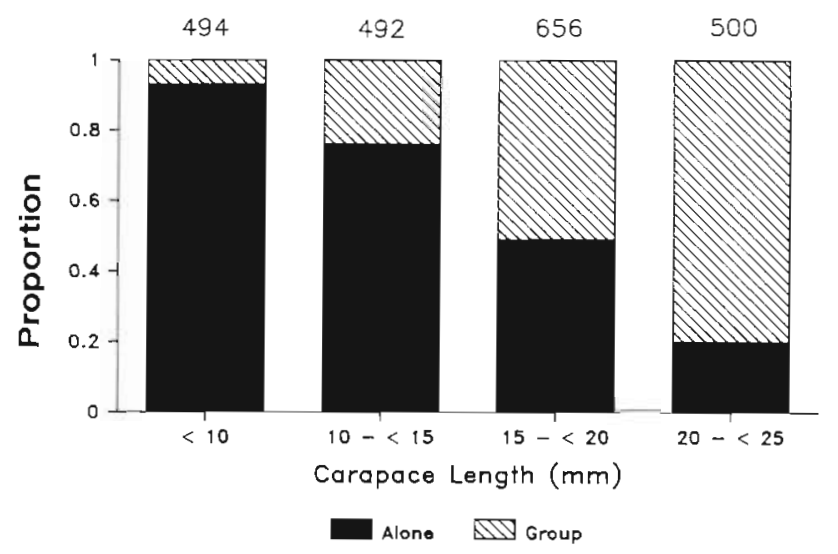

Fig. 7. Panulirus cygnus. Proportion of post-pueruli in groups or alone. Data are supplied by J. Fitzpatrick (CSIRO Marine Laboratories) and were collected at Seven Mile Beach in September 1988, November 1988, January 1989 and March 1989, pooled and then divided into 4 size classes. Numbers at the top of the histograms are the number of post-pueruli in each sample

and a total of 17 and 18 post-pueruli were recorded at the 2 sites respectively. The factor of hole size (diameter) was analysed by pooling the data over times, sites, seagrass cover and hole depth and regressing the diameter of the hole against the carapace length of the post-pueruli. The analysis is shown in Table 1 and indicates that there is a highly significant linear trend for smaller post-pueruli to be found in smaller holes.

\section{Transferral of post-pueruli}

Post-pueruli from the artificial collectors did not readily enter the natural shelters. Ten out of 20 eventually moved into the holes, tail first, after prodding by the divers. Four of these immediately walked out into the surrounding seagrass and one other left its hole 15 min later. A higher proportion of post-pueruli remained in holes in the limestone blocks compared with those transferred to natural shelters, in the first hour after

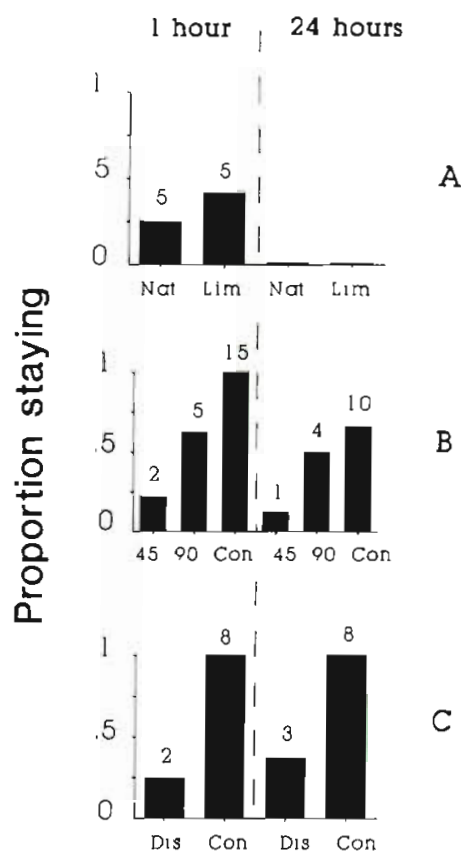

Fig. 8. Panulirus cygnus. Proportion of post-pueruli staying in shelters, $1 \mathrm{~h}$ and $24 \mathrm{~h}$ after transferral. (A) Results of transferring post-pueruli from artificial seaweed collectors to natural (Nat) or to artificial shelters in limestone blocks (Lim). Numbers on top of these and all other histograms in this figure refer to the number of post-pueruli remaining in shelters. (B) Results of transferring post-pueruli from their natural shelters and returning them by 2 different release methods, $45^{\circ}$ (45) and $90^{\circ}(90)$, compared with undisturbed control lobsters (Con). (C) Results of transferring/disturbing post-pueruli from their holes in limestone blocks (Dis) and returning them compared with undisturbed controls (Con)

release, but all individuals were absent on the following day (Fig. 8A, Table 2).

In the second experiment, fewer post-pueruli released at $45^{\circ}$ stayed within the first hour in their natural shelters compared with those released at $90^{\circ}$, and also with untransferred (undisturbed) control lobsters. The same trend was apparent on the following day (Fig. 8B, Table 2).

In the third experiment, 6 out of 8 transferred (dis-

Table 1 Panulirus cygnus. Linear regression of the carapace length of post-pueruli against the hole diameter of shelters in limestone blocks. Carapace lengths are pooled over sampling times, sites and hole depth (34 individuals were in $50 \mathrm{~mm}$ deep holes and only 1 was in a $25 \mathrm{~mm}$ hole). The regression model assumes that there is more than one carapace length measurement for each hole size (Sokal \& Rohlf 1981, p. 477)

\begin{tabular}{|c|c|c|c|c|c|c|}
\hline Source of variation & SS & $\%$ & $\mathrm{df}$ & MS & F & $\mathrm{p}$ \\
\hline Groups & 20.11 & 31.48 & 3 & 6.70 & 4.75 & $<0.010$ \\
\hline Linear & 18.82 & 93.60 & 1 & 18.82 & 29.24 & $<0.001$ \\
\hline Deviation & 1.29 & 6.40 & 2 & 0.64 & 0.46 & $>0.05$ \\
\hline Error & 43.78 & 68.52 & 31 & 1.41 & & \\
\hline Total & 63.89 & & & & & \\
\hline$Y=5.67+0.37 X$ & $R^{2}=0.94$ & & & & & \\
\hline
\end{tabular}


Table 2. Panulirus cygnus. Results of transferral experiments with post-pueruli: Experiment 1 compared whether postpueruli stay after being transferred from artificial collectors to either natural shelters or to artificial holes in limestone blocks. The response (stay/leave) was measured after $1 \mathrm{~h}$ and $24 \mathrm{~h}$. Experiment 2 compared whether post-pueruli stay after being transferred from their natural shelters and returned to the same shelters, compared to those of undisturbed control postpueruli in natural shelters. Two different release methods were used (release container held at $45^{\circ}$ or at $90^{\circ}$; see text) and the response (stay/leave) was measured after $1 \mathrm{~h}$ and $24 \mathrm{~h}$. Experiment 3 compared whether post-pueruli stay after being transferred from their own holes in limestone blocks and returned to their same holes compared with undisturbed control lobsters, and the response (stay/leave) was measured after $1 \mathrm{~h}$ and $24 \mathrm{~h}$. All post-pueruli were transferred within $3 \mathrm{~min}$ of capture and all data were analysed by 3 -factor loglinear $G$ test contingency tables

\begin{tabular}{|c|c|c|c|}
\hline Factors & $\mathrm{df}$ & G & $\mathrm{p}$ \\
\hline \multicolumn{4}{|l|}{ Experiment 1} \\
\hline Habitat $\times$ Time & 1 & 0.19 & $>0.05$ \\
\hline Time $\times$ Stay & 1 & 304.23 & $<0.001$ \\
\hline Habitat $\times$ Stay & 1 & 305.67 & $<0.001$ \\
\hline Habitat $\times$ Time $\times$ Stay & 1 & 0.00 & $>0.05$ \\
\hline \multicolumn{4}{|l|}{ Experiment 2} \\
\hline Transfer $\times$ Time & 2 & 1.62 & $>0.05$ \\
\hline Transfer $\times$ Stay & 2 & 249.83 & $<0.001$ \\
\hline Time $\times$ Stay & 1 & 245.00 & $<0.001$ \\
\hline Transfer $\times$ Time $\times$ Stay & 2 & 3.81 & $>0.05$ \\
\hline \multicolumn{4}{|l|}{ Experiment 3} \\
\hline Transfer $\times$ Time & 1 & 0.11 & $>0.05$ \\
\hline Transfer $\times$ Stay & 1 & 108.01 & $<0.001$ \\
\hline Time $\times$ Stay & 1 & 103.77 & $<0.001$ \\
\hline Transfer $\times$ Time $\times$ Stay & 1 & 0.04 & $>0.05$ \\
\hline
\end{tabular}

turbed) post-pueruli left their holes in limestone blocks within $1 \mathrm{~h}$. No control lobsters left during this time (Fig. 8C, Table 2). A similar trend was apparent on the following day but there were 3 individuals present in the 'disturbed' holes compared with 8 in the controls.

\section{DISCUSSION}

The post-pueruli of Panulirus cygnus were found in holes in the limestone reefs covered by seagrass and/or algae. Only 2 individuals were found in seagrass beds away from the reefs despite intensive sampling using suction pumps. Sweat (1968) used a variety of methods including vacuuming, pushnets and roller-frame trawls to find $P$. argus in seagrass beds and also failed to locate significant numbers of post-pueruli. The only consistently successful method of finding post-pueruli in their natural habitat has been by visual searching by divers (e.g. Serfling 1972, Engle 1979, Marx 1983).
The habitat of Panulirus cygnus at Seven Mile Beach, of holes in limestone reefs covered by seagrass, is different from that of some of the other post-pueruli in the genus. For example, P. argus is found predominantly in clumps of the red alga Laurencia (Marx \& Hernkind 1985b), although it has also been found in rock rubble (Andree 1981) and on mangrove roots (Witham et al. 1964). Post-pueruli of $P$. interruptus, however, are found in a range of habitats: shallow protected rock rubble and crevices, under boulders with an algal or seagrass covering and also in Phyllospadix seagrass beds (Parker 1972, Serfling 1972, Engle 1979). P. japonicus (von Seibold) has also been found in a range of habitats: algal clumps, rock crevices and holes in rocks and boulders (Yoshimura \& Yamakawa 1988).

The difference in the habitats of the different species of post-pueruli may be species-specific, or may be a function of the type of shelter locally available; there were no Laurencia (Marx \& Herrnkind 1985b) or boulders (Parker 1972, Yoshimura \& Yamakawa 1988) at Seven Mile Beach. Although the habitat at Seven Mile Beach is typical of the coastal habitat where adult and juvenile Panulirus cygnus are found, the lobster also occurs at the Abrolhos Islands, ca $100 \mathrm{~km}$ off the coast of Western Australia. Abundant live coral grows in waters around the islands and post-pueruli have recently been discovered living amongst the plates of live coral and in cracks and crevices of algal covered coral (J. Fitzpatrick, CSIRO Marine Laboratories, unpubl. data).

During the present study, the numbers of postpueruli of Panulirus cygnus at Seven Mile Beach in caves, ledges and the reef face changed with time from no significant difference between habitats during February 1987 , to significantly more individuals found in ledges than in caves, and more in caves than in the reef face during March-April 1987. The change in habitat preference may reflect a change in behaviour; with increased size, the lobsters become more gregarious and move into the cave and ledge habitat of the juveniles. The mechanism causing gregariousness is unknown although conspecific odour has been suggested by Zimmer-Faust \& Spanier (1987) to cause aggregation of juvenile $P$. interruptus.

The microtopography of the reef face, caves and ledges of coastal limestone reefs at Seven Mile Beach is characterised by a multitude of small holes, cracks and crevices with numerous and complex variations. Some of these habitats are occupied by post-pueruli whilst others, which appear to be suitable, and identical to occupied shelters, are unoccupied. It is, therefore, extremely difficult to identify what a post-pueruli perceives as a suitable shelter and to estimate the abundance of potential shelters. It is equally difficult to 
determine the exact dimensions of the shelters including the microtopography. This problem was discussed by Caddy (1986) who suggested experimental approaches instead of measuring the fractal dimensions of the habitat. One such approach was to use artificial substrates with a fixed number of randomly placed holes of known dimensions over a range of discrete sizes. Caddy (1986) suggested that under equilibrium conditions, the proportion of holes of a given size which are occupied will be a function of the occupancy rate of naturally occurring holes of the same size, but more easily measured. The holes drilled in the limestone blocks, which provided a suitable habitat for Panulirus cygnus, may therefore be an important experimental tool for future research to overcome the problem of determining the shelter preference of the post-pueruli in relation to shelter size.

On the limestone blocks, Panulirus cygnus preferred deeper holes and all individuals preferred blocks with a cover of Amphibolis. This suggests that the depth of hole and the cover of the shelter are important factors in habitat preference. In addition, there was a trend for smaller individuals to be associated with smaller holes. Most individuals found in natural shelters were in holes with only one entrance. It is not known whether they preferred a shelter with a single entrance or whether this type of habitat was more common, but Parker (1972) found that post-puerulus $P$. interruptus also preferred shelters with a single entrance.

Of the other designs of shelter evaluated in the present study, only those constructed of 'Tanikalon' were occupied by the post-puerulus of Panulirus cygnus. Floating collectors made of 'Tanikalon' (Phillips 1972) are also successful for collecting pueruli and post-pueruli of $P$. cygnus (Phillips 1986). Post-pueruli are also found when the collectors are moored on the seabed although in lower numbers (Phillips 1972). Similar stages of $P$. argus have also been collected on a different design of floating surface collector (Witham et al. 1964), although various designs of artificial habitat on the seabed have proved unsuccessful (Sweat 1968). Other designs of shelter which have proved successful with other species (e.g. those used by Witham et al. 1964 and Booth 1979) have been unsuccessfully tried with P. cygnus (B. Phillips, CSIRO Marine Laboratories, unpubl.). Although both the 'Tanikalon' habitats and holes in limestone blocks were successfully used by $P$. cygnus, they are very different designs of shelter It may be possible for the 'Tanikalon' habitat to accommodate lobsters as they grow, unlike the fixed hole size in the limestone blocks. 'Tanikalon' habitats may therefore be a better design of shelter catering for a continuum of sizes and growth of post-pueruli of $P$. cygnus

Although some large groups of Panulirus cygnus (up to about 100 individuals) were found in a single shelter, $75 \%$ were solitary during sampling in February 1987. This value probably varies depending upon the size range of the lobsters (see Fig. 7) and therefore the time of year that sampling takes place. In comparison with other species, Yoshimura \& Yamakawa (1988) reported that $P$. japonicus were solitary, although Herrnkind \& Butler (1986) reported that post-pueruli of $P$. argus sometimes occurred in groups.

Movement of Panulirus cygnus between shelters appeared to be common, as $50 \%$ of the occupied shelters were vacated after only $1 \mathrm{~d}$. It is not known where the lobsters went because they could not be individually marked and identified in other shelters. However, they may remain on the isolated patch reefs where there is shelter, because if they tried to move between reefs they would be exposed to a high risk of predation (Howard 1988). Howard (1988) found that predation by fish on the nursery reefs at Seven Mile Beach was concentrated on post-pueruli between 8 and $15 \mathrm{~mm} \mathrm{CL}$. He estimated that fish predators annually remove thousands of lobsters per hectare and suggested that predation may be a major factor limiting the survival of $P$. cygnus on the nursery reefs.

In contrast to the movements of post-pueruli of Panulirus cygnus between shelters, $P$. japonicus is reported to remain in the same shelters for up to 12 mo (Yoshimura \& Yamakawa 1988), and Engle (1979) found that 381 out of 433 post-pueruli of $P$. interruptus were recaptured in the same general area where they were first marked. $P$. argus was reported to move from shelters by Herrnkind \& Butler (1986). These authors also found that between 26 and $83 \%$ of post-pueruli of $P$. argus dispersed overnight from algal clumps where they had been placed, although it is not known. whether this dispersion from the shelters was as a result of transferral. In the case of $P$. cygnus the proportion remaining after transfer may be a function of the degree of disturbance (see Fig. 8B). The proportion of $P$. cygnus remaining after transfer by divers to their own or other shelters varied depending on the method of release. Post-pueruli transferred from artificial collectors to what appeared to be ideal shelters did not stay, but moved off into the surrounding seagrass.

In the present study, post-pueruli of Panulirus cygnus have been found in their natural habitat by the extensive use of divers. As a result, it was possible to investigate their habitat preference and behavioral patterns and future studies of their growth rate, feeding patterns and population dynamics are also possible. The rejection of shelters by post-pueruli immediately after transferral may be a significant problem in areas of high natural predation. Further studies of transferral techniques could be of value in minimising such rejection. In experiments where post-pueruli were allowed 
to select artificial shelter without being transferred, 2 designs of artificial shelters, those made of 'Tanikalon' and the holes in limestone blocks with seagrass cover, were successfully utilised. This indicates that such habitats may be of value in enhancing the survival of post-pueruli where natural shelter is limited.

Acknowledgements. Field assistance was provided by K. Smith, S. Finn, J. Fitzpatrick, M. Forde, and A. Hancock. Thanks go to J. Fitzpatrick for the use of his data in Fig. 7 and to B. F. Phillips, V. Mawson, F. R. Harden Jones, L. Joll, J. Trendall and an anonymous referee for comments on the manuscript. This study was funded by a Commonwealth grant from the Fishing Industry Research Trust Account, Grant $1986 / 83$.

Appendix 1 Species of algae found as cover around shelters of post-pueruli

\begin{tabular}{|ll|}
\hline Alga & Taxonomic authority \\
\hline Amphiroa anceps & (Lamour) Decne. \\
Botrycladia obvata & (Sond.) Kylin \\
Caulerpa cactoides & (Turner) C.Ag. \\
Caulerpa obscura & Sonder \\
Caulerpa racemosa & (Turner) Bosse \\
Caulerpa vesiculifera & Harvey \\
Corallina cuvieri & Lamouroux \\
Hypnea cervicornis & J.Ag. \\
Laurencia filiformis & (C.Ag.) Harv. \\
Lenormandia spectabilis & Sonder \\
Lobospira bicuspidata & Aresch. \\
Metagoniolithon stelliferum & (Lamk.) Bosse \\
Metamastophora flabellata & (Sond.) Setchel \\
Rhodymenia australis & (Sond.) Harv. \\
Struvea plumosa & (Sond.) Harv. \\
Zonaria turneriana & J.Ag. \\
\hline
\end{tabular}

\section{LITERATURE CITED}

Andree, S. W. (1981). Locomotory activity patterns and food items of benthic postlarval spiny lobsters, Panulirus argus. M.Sc. thesis, Florida State University

Booth, J. D. (1979). Settlement of the rock lobster, Jasus edwardsii (Decapoda: Palinuridae), at Castlepoint, New Zealand. N.Z. Jl mar Freshwat. Res. 13: 395-406

Caddy, J. F. (1986). Modelling stock-recruitment processes in Crustacea: some practical and theoretical perspectives. Can. J. Fish. aquat. Sci. 43: 2330-2344

Chittleborough, R. G. (1970). Studies on recruitment in the western Australian rock lobster Panulirus longipes cygnus George: density and natural mortality of juveniles. Aust. J. mar Freshwat. Res. 21. 131-148

Chittleborough, R. G., Thomas, L. R. (1969). Larval ecology of the Western Australian marine crayfish, with notes upon other panulirid larvae from the eastern Indian Ocean. Aust. J. mar. Freshwat. Res. 20: 199-223

Chittleborough, R. G., Phillips, B. F. (1975). Fluctuations of year-class strength and recruitment in the western rock lobster Panulirus longipes (Milne-Edwards). Aust. J mar. Freshwat. Res. 26: 317-328
Chittleborough, R. G., Phillips, B. F. (1979). Recruitment to the catchable stock of the western rock lobster Panulirus longipes cygnus George. Rapp. P.-v. Réun. Cons. int. Explor Mer 175: 139-142

Cobb, J. S. (1981). Behaviour of the Western Australian spiny lobster, Panulirus cygnus George, in the field and laboratory. Aust. J. mar Freshwat. Res. 32: 399-409

Engle, J. M. (1979). Ecology and growth of juvenile California spiny lobster, Panulirus interruptus (Randall). Ph.D. thesis, University of Southern California

Hernkind, W F., Butler IV., M. J. (1986). Factors regulating postlarval settlement and juvenile microhabitat use by spiny lobsters Panulirus argus. Mar Ecol. Prog. Ser. 34: 23-30

Howard, R. K. (1988). Fish predators of western rock lobster (Panulirus cygnus George) in a nearshore nursery habitat. Aust. J. mar Freshwat. Res. 39: 307-316.

Jernakoff, P., Phillips, B. F., Maller, R. A. (1987). A quantitative study of nocturnal foraging distances of the western rock lobster Panulirus cygnus George. J. exp. mar. Biol. Ecol. 113: 9-21

Joll, L. M. (1982). Foregut evacuation of four foods by the western rock lobster Panulirus cygnus in aquaria. Aust. J. mar. Freshwat. Res. 33: 939-943

Lewis, J. B., Moore, H. B., Babis, W. (1952). The postlarval stages of the spiny lobster Panulirus argus. Bull. mar. Sci. 2: $324-337$

Marx, J. (1983). Aspects of microhabitat use by young juvenile spiny lobsters, Panulirus argus. M.Sc. thesis, Florida State University, Tallahassee

Marx, J. M., Herrnkind, W. F. (1985a). Factors regulating microhabitat use by young juvenile spiny lobsters, Panulirus argus: food and shelter J. Crustacean Biol. 5: 650-657

Marx, J. M., Herrnkind, W. F. (1985b). Macroalgae (Rhodophyta: Laurencia spp.) as habitat for young juvenile spiny lobsters, Panulirus argus. Bull. mar. Sci. 36: 423-431

Morgan, G. R. (1979). Assessment of the studies of the western rock lobster, Panulirus cygnus, using surplus yield models. Aust. J. mar. Freshwat. Res. 30: 355-363

Morgan, G. R., Phillips, B. F., Joll, L. M. (1982). Stock recruitment relationships in Panulirus cygnus the commercial rock (spiny) Iobster of Western Australia. Fish. Bull. U.S. 80: $475-486$

Parker, K. P. (1972). Recruitment and behaviour of puerulus larvae and juveniles of the California spiny lobster Panulirus interruptus (Randall). M.Sc. thesis, San Diego State University

Phillips, B. F. (1972). A semi-quantitative collector of the puerulus larvae of the western rock lobster Panulirus longipes cygnus George (Decapoda, Palinuridae). Crustaceana 22: $147-154$

Phillips, B. F. (1986). Prediction of commercial catches of the western rock lobster Panulirus cygnus. Can. J. Fish. aquat. Sci 43: 2126-2130

Phillips, B. F., Scolaro, A. B. (1980). An electrofishing apparatus for sampling sublittoral benthic marine habitats. J. exp. mar Biol. Ecol. 47. 69-75

Phillips, B. F., Campbell, N. A., Rea, W. A. (1977). Laboratory growth of early juveniles of the Western rock lobster Panulirus longipes cygnus. Mar Biol. 39: 31-39

Phillips, B. F., Joll, L. M., Ramm, D. C. (1984). An electromagnetic tracking system for studying the movements of rock (spiny) lobsters. J. exp. mar Biol. Ecol. 79: 9-18

Serfling, S. A. (1972). Recruitment, habitat preference, abundance and growth of the puerulus and early juvenile stages of the California spiny lobster, Panulirus interruptus (Randall). M.Sc. thesis, San Diego State University 
Sheard, K. (1962). The Western Australian crayfishery, 1944-1961. Peterson Brokensha Pty, Ltd., Perth, Australia Sokal, R. R., Rohlf, F. J (1981). Biometry. The principles and practice of statistics in biological research. W H. Freeman and Company, San Francisco

Sweat, D. A. (1968). Growth and tagging studies on Panulirus argus (Latrielle) in the Florida Keys. Fla Bd Conserv. Tech. Ser. 57: $1-30$

Witham, R., Ingle, R. M., Sims, H. W Jr (1964). Notes on

This article was submitted to the editor postlarvae of Panulirus argus. Q. Jl Fla Acad. Sci. 24: 289-297

Yoshimura, T., Yamakawa, H. (1988). Ecological investigations of settled puerulus and juvenile stages of the Japanese spiny lobster Panulirus japonicus at Kominato, Japan. J. Crustacean Biol. 8: 524-531

Zimmer-Faust, R. K., Spanier, E. (1987). Gregariousness and sociality in spiny lobsters: implications for den habitation. J. exp. mar Biol. Ecol. 105: 57-71

Manuscript first received: January 23, 1990 Revised version accepted: June 25, 1990 